\title{
Biological and Mechanical Heart Valves Under a New Spotlight: Paradigm Shift and New State of the Art
}

\author{
Domingo Marcolino Braile $\mathrm{e}^{1,2(1)}$ and Idiberto José Zotarelli Filho ${ }^{10}$ \\ Domingo Braile Institute of São José do Rio Preto (SP), ${ }^{1}$ São José do Rio Preto, SP - Brazil \\ Braile Biomédica, ${ }^{2}$ São José do Rio Preto, SP - Brazil
}

With the growth in life expectancy observed in recent decades in Brazil and worldwide, implantation of cardiac valve prostheses has been one of the recommended procedures for patients with valve diseases. In Brazil, this approach is the second most performed surgery among highly complex cardiovascular procedures. According to DATASUS, between January 2008 and May 2018, 900 implants were performed. ${ }^{1}$

The 2017 European Society of Cardiology / European Association for Cardio-Thoracic Surgery (ESC/EACTS3) guidelines established that the choice between a mechanical (MV) and biological valve (BV) in adults is primarily determined by estimating the risk of bleeding related to anticoagulation, thromboembolism, and the risk of structural deterioration of $\mathrm{BV}$, considering the patient's lifestyle and preferences. ${ }^{2}$ This risk/benefit ratio of MV and BV led the US and European guidelines to recommend the use of prostheses in patients under 60 years of age. Nevertheless, the use of BV has increased significantly in all age groups in recent decades. ${ }^{2}$

The recently published paper entitled "Bioprosthesis versus Mechanical Valve Heart Prosthesis: Assessment of Quality of Life" 3 assessed the quality of life (QoL) using the short form (SF)-36 questionnaire of 36 consecutive patients (16 men), mean age 51 years, who underwent heart valve replacement. After an average time of 32.5 months, the study showed that the type of prosthesis did not seem to influence patients' QoL. Also, another

\section{Keywords}

Heart Valve Diseases/surgery; Heart Valve Prosthesis Implantation/methods;Trancathter Aortic Valve Replacement (TAVR)/methods; Minimally Invasive Surgical Procedures/trends. study on QoL (SF-36) included 121 consecutive patients undergoing BV (76.5\%) and MV (86,3,1\%). No significant differences were found between valve groups for any aspects of QoL. ${ }^{4}$

Kottmaier et al., ${ }^{5}$ compared QoL and anxiety of 56 patients after mechanical aortic valve replacement (AVR) (mean age: $64.4 \pm 8.17$ years) and 66 patients after biological AVR (mean age: $64.8 \pm 11.05$ years. After 5.66 $( \pm 2.68)$ years of surgery, patients received the SF-36 to assess QOL, the fear of progression questionnaire (FOP), and the cardiac anxiety questionnaire (CAQ) to assess general anxiety. No significant differences were found for all categories of the SF-36. The FOP showed significantly favorable values for the biological AVR group. The CAQ showed a tendency towards more favorable values in the subscales "avoid" (i.e, avoid pulse increase) and "attention" for the biological AVR group. ${ }^{5}$

A systematic review and meta-analysis were performed to compare long-term survival, major prosthetic-related events, anticoagulant-related events, major bleeding, reoperation, and structural valve degeneration in middle-aged patients who received BV or MV. Results from patients under 70 years of age undergoing AVR with BV or MV were included. A total of 12 studies involving 8,661 patients was analyzed. There was no significant difference in long-term survival between patients 50 to 70 or 60 to 70 years. BV patients had significantly fewer long-term anticoagulant-related events. Also, studies have supported the use of BV in patients over 60 years of age. ${ }^{6}$

In this sense, scientific progress may increase the acceptance level for conservative aortic valve surgery using bovine pericardium valve (BPV). One study reported a long-term follow-up (23 years) of a patient who underwent surgery on the BPV cusp extension. ${ }^{7}$

Mailing Address: Idiberto José Zotarelli Filho

Rua Luiz Vaz de Camões, 3111. Postal Code: 15015-750, Vila Redentora, São José do Rio Preto, SP - Brazil.

E-mail: m.zotarelli@gmail.com 
Increasing confidence in the effectiveness of the operation has allowed a faster indication for surgical treatment, as is already the case in mitral valve repair. This change of attitude will allow patients with mild aortic valve regurgitation to be referred for surgery, which can positively alter the natural history of aortic valve insufficiency. ${ }^{7}$

In the setting of transcatheter AVR (TAVR) as a minimally invasive alternative to surgical AVR (SAVR), Chakravarty et al., ${ }^{8}$ aiming to elucidate the greater propensity of using bioprostheses in relation to anticoagulation, evaluated the impact of anticoagulation after aortic valve replacement. Echocardiograms were performed 30 days and 1 year after TAVR. A total of 4,832 patients underwent TAVR $(3,889)$ and SAVR (943). In the short term, early anticoagulation after biological AVR did not result in adverse clinical events, did not significantly affect aortic valve hemodynamics and was associated with decreased rates of stroke after SAVR.

In this context, transcatheter valve-in-valve (ViV) implantation has been increasingly used in recent years, especially with BPV. A 2019 study evaluated 30-day and 1 -year mortality and the incidence of adverse outcomes in patients receiving ViV or re-SAVR. Despite a higher risk profile in $\mathrm{ViV}, 30$-day and 1-year mortality rates were no different compared to re-SAVR, which may be explained by a higher rate of re-SAVR complications. Therefore, $\mathrm{ViV}$ seems to be a safe and viable therapeutic option for patients with degenerated aortic bioprosthesis. ${ }^{9}$

Also, two randomized clinical trials have been published, the Evolut Low-Risk study ${ }^{10}$ and the PARTNER 3 study compared TAVR and SAVR in patients who are low surgical risk. ${ }^{11}$ The mean age in both trials was 74 years. Patients who had undergone TAVR showed lower rate of death, stroke, rehospitalization or complications than surgery. Altogether, these results indicate that TAVR may be indicated not only for patients with lower surgical risk, but also for younger patients.

Thus, TAVR and ViV procedures are advancing, and in the coming years, there will likely be an even stronger change in the treatment of patients with valve diseases, in operating rooms and cath labs. Recent findings in the literature corroborate a shift in the paradigm to the use of bioprostheses, especially with the advent of PBV and advances in $\mathrm{ViV}$ implantation for aortic valve prosthesis failure, recognizing them as state-of-the-art therapies.

\section{References}

1. Brasil. Ministério da Saúde [Internet]. DATASUS. Procedimentos hospitalares do SUS - por gestor - Brasil [acesso em 17 jul 2018]. Disponível em: http://tabnet.datasus.gov.br/cgi/tabcgi.exe?sih/cnv/qgbr. def.

2. Head SJ, Çelik M, Kappetein AP. Mechanical versus bioprosthetic aortic valve replacement. Eur Heart J. 2017;38(28):2183-91.

3. Molero Junior JC, Raimundo RD, Amaral JAT, Abreu LC, Breda JR. Bioprosthesis versus Mechanical Valve Heart Prosthesis: Assessment of Quality of Life. Int J Cardiovasc Sci. 2020;33(1):36-42.

4. Repack A, Ziganshin BA, Elefteriades JA, Mukherjee SK. Comparison of quality of life perceived by patients with bioprosthetic versus mechanical valves after composite aortic root replacement. Cardiology. 2016;133(1):3-9

5. Kottmaier M, Hettich I, Deutsch MA, Badiu C, Krane M, Lange R, et al. Quality of life and anxiety in younger patients after biological versus mechanical aortic valve replacement. Thorac Cardiovasc Surg. 2017;65(3):198-205.

6. Zhao DF, Seco M, Wu JJ, Edelman JB, Wilson MK, Vallely MP, et al. Mechanical versus bioprosthetic aortic valve replacement in middle-

aged adults: a systematic review and meta-analysis. Ann Thorac Surg. 2016;102(1):315-27.

7. Evora PRB, Arcêncio L, Evora PM, Menardi AC, Chahud F. Bovine pericardial patch augmentation of one insufficient aortic valve cusp with twenty-three-year positive clinical follow-up independent of the patch degeneration. Braz J Cardiovasc Surg. 2017;32(1):49-52.

8. Chakravarty T, Patel A, Kapadia S, Raschpichler M, Smalling RW, Szeto WY, et al. Anticoagulation after surgical or transcatheter bioprosthetic aortic valve replacement. J Am Coll Cardiol. 2019;74(9):1190-1200.

9. Stachel G, Woitek FJ, Holzey D, Kiefer P, Haussig S, Leontyev S, et al. Treatment of degenerated aortic bioprostheses: a comparison between conventional reoperation and valve-in-valve transfemoral transcatheter aortic valve replacement. Eur Heart J. 2018;39(suppl 1):ehy564.234.

10. Popma JJ, Deeb GM, Yakubov SJ, Mumtaz M, Gada H, O'Hair D, et al. Transcatheter aortic-valve replacement with a self-expanding valve in low-risk patients. N Engl J Med. 2019;380(18):1706-15.

11. Mack MJ, Leon MB, Thourani VH, Makkar R, Kodali SK, Russo M, et al. Transcatheter aortic-valve replacement with a balloon-expandable valve in low-risk patients. N Engl J Med. 2019;380(18):1695-705. 